\title{
Fidelidade em cooperativa agropecuária: Um estudo de caso
}

\author{
Fidelity in agricultural cooperative: A case study
}

\begin{abstract}
Resumo
Esse estudo teve como objetivo avaliar a fidelidade dos cooperados numa cooperativa agropecuária gaúcha quanto à entrega ou não de sua produção, na safra 2012/2013. Utilizou-se o método qualitativo, desenvolvido através de um estudo de caso na Cooperativa Tritícola Sepeense Ltda - COTRISEL. O estudo consistiuse de uma pesquisa aplicada (bibliográfica, documental e direta), de caráter exploratório, visando gerar informações de aplicação prática a respeito dos motivos que levaram os cooperados a depositarem parcial ou totalmente sua produção de soja na cooperativa. A pesquisa classificou o cooperante de acordo com sua fidelidade na entrega da produção de soja na cooperativa. Ao final da pesquisa concluiu-se que, de maneira geral, 63,9\% dos cooperados entrevistados foram fiéis à cooperativa. Outros 16,7\% foram moderadamente fiéis; 11,1\% foram pouco fiéis; e por fim, 8,3\% foram infiéis. $O$ estudo permitiu concluir que os principais fatores que estimularam a fidelidade dos associados estão relacionados com a confiança, a honestidade e a credibilidade da cooperativa, pontualidade nos pagamentos, estrutura de armazenagem, assistência técnica, prazo de pagamento dos insumos para safra (financiamento do cooperado), afinidade com a cooperativa, distribuição das sobras líquidas conforme estatuto social e contratos de troca-troca (grão por insumos). Os fatores que desestimularam a fidelidade, relatados pelos cooperados, foram os descontos praticados pela cooperativa na hora da entrega da produção de soja, o preço pago pela soja (muitas vezes o cooperado encontra preços mais competitivos em outros estabelecimentos) e uma falta de agilidade no recebimento e descarga da soja.
\end{abstract}

Palavras-chave: Cooperativismo. Cooperativas agropecuárias. Fidelidade.

\begin{abstract}
This study aimed to evaluate the loyalty of cooperative members in a state's agricultural cooperative 'delivery or not of its production in 2012/2013 harvest. We used the qualitative method, developed through a case study on Cooperative Tritícola Sepeense Ltda - COTRISEL. The study consisted is an applied research (bibliographical, documentary and direct), exploratory, aimed at generating practical application of information regarding the reasons that led the cooperative to deposit part or all their soybean production in the cooperative. The survey ranked the cooperative according to their faithfulness in delivery of soybean production in the cooperative. At the end of the study it was concluded that, overall, 63,9\% of respondents were cooperative members loyal to the cooperative. Other 16,7\% were moderately faithful; 11,1\% were less faithful; and finally, 8,3\% were unfaithful. The study found that the main factors that encouraged the loyalty of the members are related to the trust, honesty and credibility of the cooperative, punctual payments, storage structure, technical assistance, payment term of inputs to crop (financing cooperated), affinity with the cooperative, distribution of net profits as social status and exchange-exchange contracts (grain for inputs). The factors that discouraged loyalty, reported by members, were the discounts granted by the cooperative at the time of delivery of soybean production, the price paid for soybeans (often cooperated find more competitive pricing in other establishments) and a lack of flexibility in receiving and soybean discharge..
\end{abstract}

Key words: Cooperativism. Agricultural cooperatives. Fidelity.

Recebido: 21/10/2015 Aceito: 06/01/2016

Gustavo Fontinelli Rossés ${ }^{1}$, Marcelo Tomazi ${ }^{2}$, Fabiana Letícia Pereira Alves Stecca ${ }^{3}$, Douglas Cavalheiro de Oliveira ${ }^{4}$ e Carla Rosane da Costa Sccott ${ }^{5}$

${ }^{1}$ Universidade Federal de Santa Maria, Doutorado em Extensão Rural - gustavo@politecnico.ufsm.br-Rua José Paulo

Teixeira, 125,Bairro Camobi, Santa Maria, CEP 97110-750

${ }^{2}$ Universidade Federal de Santa Maria, Graduação em Gestão de Cooperativas - mtomazi@ cotrisel.com.br

${ }^{3}$ Universidade Federal de Santa Maria, Mestrado em Engenharia de Produção- fabiana@ufsm.br

${ }^{4}$ Universidade Federal de Santa Maria, Graduação em Gestão de Cooperativas - douglas@ cotrisel.com.br

${ }^{5}$ Universidade Federal de Santa Maria ,Mestrado em Engenharia de Produção - carlasccott@ gmail.com 


\section{Introdução}

$\mathrm{A}$ s cooperativas agropecuárias ocupam lugar de destaque no agronegócio brasileiro, com números expressivos em relação ao volume de produção comercializado, número de associados, exportação de produtos e empregos gerados. Conforme dados da OCB (2012) o segmento do cooperativismo agropecuário é composto por 1.523 cooperativas, 969.541 cooperados e 155.896 empregados.

De acordo com o aspecto social e econômico, o cooperativismo se consolidou como um sistema de geração de renda e de inclusão social, a um universo superior a 10 milhões de cooperados. A grande dimensão econômica do sistema cooperativista é inegável, visto que neste mesmo ano, as cooperativas brasileiras registraram um resultado recorde em vendas ao exterior, alcançando US\$ 6,1 bilhões em exportações, com crescimento de $39,8 \%$ em relação ao ano anterior (OCB, 2012).

Segundo Waack e Machado (1999, p. 149), “tão grande quanto esses números apresentados são os desafios crescentemente enfrentados por todo o sistema cooperativista, para sobreviver no novo ambiente competitivo e manter-se fiel ao cumprimento de seus princípios doutrinários".

O cenário econômico mundial tem experimentado mudanças radicais nas últimas décadas, tais como o aumento da competitividade, o desenvolvimento tecnológico e a mudança de comportamento do consumidor. Tais transformações afetam sobremaneira o setor agropecuário brasileiro, elo fundamental de um complexo agroindustrial maior chamado de agribusiness. As organizações passam por intensas transformações nunca antes imaginadas, envolvendo todos os campos onde ela influencia ou sofre interferências.

Na visão de Simioni et al. (2009, p. 740), “as cooperativas agrícolas passaram, e estão passando, por adequações em suas posturas diante da realidade de mudanças constantes no mercado competitivo, uma vez que foram criadas e cresceram no período em que predominava a agricultura tradicional".

As cooperativas são organizações que promovem o desenvolvimento do setor agropecuário brasileiro e de seus cooperados, através de orientações qualificadas e confiáveis. Assim sendo, as cooperativas possuem um papel importante, ou seja, organizam e aproximam o produtor rural do consumidor final, fortalecendo os pequenos agricultores.

Em sua analogia, Rosalem et al. (2009) comentam que o cooperativismo tem como desafios, resgatar a cultura cooperativista que vem sendo esquecida pelos seus membros, necessidade de capacitação profissional dos executivos e profissionais das cooperativas, bem como dos cooperados. Ainda, relata que a união esta dando lugar aos interesses particulares. Os cooperados estão perdendo a motivação, a participação e o comprometimento com a cooperativa.

Nesse sentido, a fidelidade dos cooperados é fundamental para o crescimento e desenvolvimento de uma organização cooperativa. Para Móglia et al. (2004, p. 1) "a fidelidade e reciprocidade dos associados são comportamentos baseados em compromissos, responsabilidades e obrigações". Simioni et al. (2009) contribui definindo lealdade no âmbito cooperativo como o cumprimento de um compromisso ético e moral para com os demais membros da sociedade cooperativa.

$\mathrm{Na}$ literatura, é consenso a importância do tema fidelidade. No entanto, estudos recentes envolvendo cooperativas agropecuárias ainda são incipientes. Dessa forma, é justificadamente importante investigar as razões determinantes que cercam os sócios cooperados no momento da entrega ou não da sua produção na cooperativa.

Nos últimos anos, no município de Restinga Sêca-RS, a cultura da soja apresentou enorme crescimento em área plantada, de produtividade e de valorização do grão no mercado. Juntamente com esse crescimento, ocorreu um acirramento muito forte com os concorrentes (empresas mercantis e outras cooperativas), no que se refere ao recebimento e comercialização da soja. Muitos destes instalaram unidades de recebimento deste cereal, dentro da área de atuação da cooperativa, tendo como consequência o aumento da infidelidade por parte dos cooperados. A cooperativa perdeu parte dos grandes produtores de soja para as empresas privadas, atraídos por benefícios econômicos imediatos, prometidos por estas.

Assim sendo, consiste no objetivo geral deste estudo, identificar os motivos que levaram os cooperados da COTRISEL - Unidade de Restinga Sêca/RS, a depositarem sua produção de soja na cooperativa. Nesse sentido, o presente artigo estudará o aspecto do comprometimento quanto à deci- 
são do associado de entregar ou não sua produção à cooperativa. Os objetivos específicos foram à definição de um sistema de classificação do cooperado quanto à fidelidade na entrega de soja, apontar quais os fatores mais estimulam e quais desestimulam a fidelidade do cooperado para com a sua cooperativa.

$\mathrm{O}$ estudo divide-se em cinco seções, incluindo esta introdução. Na segunda parte, com base na literatura consultada, buscou-se um breve histórico das origens do cooperativismo, definição de alguns termos e levantamento de hipóteses sobre os fatores determinantes do grau de comprometimento dos cooperados para com a cooperativa. A metodologia utilizada é descrita na terceira seção. A discussão dos resultados obtidos compõe a quarta seção. Finalmente, a seção 5 relata as considerações finais do estudo.

\section{Revisão Bibliográfica}

No século XIX, os problemas criados pelo capitalismo eram evidentes, como por exemplo, as péssimas condições de trabalho, exploração do trabalho infantil e feminino, salários muito baixos, jornadas de trabalho exageradas, ausência de benefícios e castigos físicos aos empregados. Assim, influenciados por socialistas utópicos como Owen, Fourier, Buchez e Blanc, 28 tecelões fundaram na Inglaterra, em 1844, a primeira cooperativa que obteve êxito. Tratava-se de uma cooperativa de consumo intitulada Sociedade dos Probos Pioneiros de Rochdale. O sucesso de "Rochdale" impulsionou os movimentos cooperativistas pelo mundo a fora, contagiados pelos seus valores e princípios que, com pequenas alterações, são amplamente adotados pelas cooperativas na atualidade.

As cooperativas são associações autônomas de pessoas que se unem voluntariamente e constituem uma empresa, de propriedade comum, para satisfazer aspirações econômicas, sociais e culturais. Baseiam-se em valores de ajuda mútua, solidariedade, democracia, participação e autonomia. Os valores definem as motivações mais profundas do agir cooperativo, sendo a instância inspiradora dos princípios do Movimento Cooperativista Mundial (SCHMIDT \& PERIUS, 2003, p. 63).

A Aliança Cooperativa Internacional - ACI traz a seguinte descrição de cooperativa: "É uma associação autônoma de pessoas que se unem voluntariamente para satisfazer as aspirações e neces- sidades econômicas, sociais e culturais comuns, por meio de uma empresa de propriedade coletiva e democraticamente gerida" (OCERGS, 2012, p. 1).

As sociedades cooperativas estão reguladas pela Lei Federal $\mathrm{n}^{\circ}$ 5.764, de 1971, que define a Política Nacional de Cooperativismo e instituiu o regime jurídico das cooperativas.

O cooperativismo é uma espécie de terceira via entre o estado e o mercado, agindo em defesa dos interesses de seus cooperados, promovendo a preservação da moral e dos bons costumes, maior convívio entre seus membros e evitando a perda da liberdade dos indivíduos.

Na concepção de Rosalem et al. (2009, p. 53), “é preciso ter em mente que não são as pessoas a razão do sucesso ou fracasso das empresas cooperativas, e sim a capacidade destas cooperarem entre si para construírem algo maior que suas limitações e seus sonhos individuais". Portanto, o grande desafio da atualidade é a cooperação, visto que as pessoas estão cada vez mais individualistas, procurando buscar, na maioria das vezes, soluções tecnológicas para os problemas. Busca-se maximizar a produção, deixando o ser humano em segundo plano.

O cooperativismo defronta-se agora com novos desafios. Um deles diz respeito à questão social e econômica, visto que o mesmo nasceu sob a ótica da cooperação, ajuda mútua e de solidariedade. Porém, é preciso encontrar razões para seguir cooperando dentro de uma sociedade predominantemente mercantilista, como a nossa. As cooperativas disputam "a lealdade de seus associados tanto com outras cooperativas como com as empresas privadas, devendo oferecer elementos que proporcionem satisfação, confiança e valores, que se constituem em condutores à lealdade" (SIMIONI et al., 2009, p. 741).

No entendimento de Bork (2011), o cooperativismo é um movimento que objetiva o crescimento econômico juntamente com o bem estar social local de seus membros, tendo como alicerce a participação democrática, a solidariedade, a independência e a autonomia.

Uma doutrina socioeconômica fundamentada na liberdade humana e nos princípios cooperativos. A cultura cooperativista visa a desenvolver a capacidade intelectual das pessoas de forma criativa, inteligente, justa e harmônica, procurando a sua melhoria contínua. Os seus princípios buscam, pelo resultado econômico, o desenvolvimento social através da melhoria da qualidade de vida e da boa convivência entre seus cooperados (OCERGS, 2012, p. 1). 
Através do cooperativismo, as pessoas buscam soluções conjuntas para problemas diversos. De acordo com os princípios, a organização cooperativa necessita ser gerida de forma correta e eficiente, visando atingir resultados econômicos satisfatórios. Pois, sem o econômico, não se consegue trazer melhorias sociais para os cooperados, quais sejam à qualidade de vida e de convivência do quadro associativo.

Simioni et al. (2009), destaca que os gestores de cooperativas precisam "Pensar Capital e Agir Social". Os mesmos necessitam compreender que ninguém associa-se a uma cooperativa simplesmente porque é bonito. A motivação, na grande maioria das vezes, é financeira, ou seja, obtenção de vantagens competitivas perante as empresas tradicionais. O espírito é social, mas a motivação é capital. Para Móglia et al. (2004, p. 9), "a relação do cooperado com a cooperativa deve considerar o interesse econômico do cooperado, motivação esta que pode preponderar em determinadas situações".

A infidelidade dos cooperados é um problema sério, que compromete a situação econômica da cooperativa, podendo levá-la a dificuldades financeiras e autoliquidação. Segundo Faria (1995), a falta de espírito associativo, o baixo nível cultural e a desinformação fazem com que os cooperados não percebam as vantagens de ser um cooperado, gerando um ambiente desagradável, onde a insatisfação e a desunião acabam prevalecendo.

Nas palavras de Azevedo; Orellano; Serigati (2008, p. 3), "fidelidade é entendida como o comprometimento de um associado para com sua cooperativa. Esse comprometimento se refere ao compromisso de entregar sua produção, participação nos processos de tomada de decisão, envolvimento com as rotinas e assuntos da organização".

Este trabalho de conclusão de curso estudou o aspecto do comprometimento quanto à decisão do associado de entregar ou não sua produção à cooperativa.

A lealdade é mais do que um longo relacionamento de um cliente com uma determinada empresa ou visitas frequentes a um mesmo estabelecimento. Lealdade é um sentimento de afinidade ou ligação com produtos ou serviços de uma empresa; ela se manifesta quando os clientes gastam ou concentram a maior parte ou a totalidade de seus orçamentos com a empresa (SIMIONI et al., 2009, p. 745).
Em seu estudo sobre fidelidade e lealdade com uma cooperativa agropecuária gaúcha, Melesko (2012), concluiu que os principais fatores que contribuíram para a lealdade dos associados estão relacionados com a confiança e a credibilidade da cooperativa, boa qualidade da assistência técnica, bom atendimento e bom preço dos produtos oferecidos pela cooperativa. A variável estrutura de recebimento da produção também foi citada pelos cooperados. O mesmo estudo apontou também, como fatores inibidores da lealdade, os descontos praticados pela cooperativa na hora da entrega da produção, convívio familiar e informal com comerciantes da região e os contratos de "soja verde" oferecido pela concorrência.

Para Móglia et al. (2004), em seus estudos com uma Cooperativa Agropecuária Mista da Região de Orlândia (CAROL), na safra 2001/02, concluíram que a entrega de soja acima de $70 \%$ na CAROL se deu pelos seguintes motivos, respectivamente: entrega habitual na cooperativa, afinidade com a com a cooperativa, confiabilidade, assistência técnica permanente no campo, balança, classificação e presença da cooperativa o ano todo ao lado do produtor. Os mesmos autores revelaram nesse estudo, os principais motivos da infidelidade para com a CAROL, a saber: obtenção de melhor preço pela soja no concorrente, ajuda no frete por parte do concorrente, outras modalidades comerciais propostas por empresas da região, cliente habitual do concorrente e financiamento do cooperado por outras empresas.

Através de um estudo de caso com uma cooperativa de granjeiros, no estado de Minas Gerais, Rosalem et al. (2009) verificaram que os cooperados foram unânimes em relação à importância de sua fidelidade para com a cooperativa. No entanto, na prática, as obrigações não estão sendo exatamente cumpridas. Algumas cooperativas, em anos de excesso de produção, não conseguem absorver todo o produto oriundo de seu quadro associativo, desobrigando-os a ser totalmente fiéis. Tal fato contribui para um afastamento de parte de seus cooperados, sendo mais difícil e oneroso para a cooperativa, reconquistá-los posteriormente.

Simioni et al. (2009), trabalhando com cooperativas agropecuárias, de infra-estrutura, de serviços e de crédito, nas regiões oeste e planalto sul Catarinense, e região de Campinas (SP) concluíram que na percepção dos cooperados as variáveis mais importantes na manutenção da lealdade dos mesmos 
são, respectivamente: atendimento ao cooperado, confiança na cooperativa, qualidade, prazo de pagamento, crédito dos cooperados, imagem da organização, preço e condições de pagamento. As variáveis que mais interferem na ação dos cooperados estão vinculadas a valores mercantis (preço, crédito e condições de pagamento), com exceção do atendimento e da confiança.

Outra revelação importante da pesquisa diz respeito à interpretação sobre fidelidade, onde para os dirigentes da cooperativa, o cooperado fiel é aquele que comercializa toda sua produção com a cooperativa; participam das reuniões, assembleias e eventos; confia e defende a cooperativa; cumpre seus deveres e exige seus direitos, conforme o estatuto; e valoriza a cooperativa. Em contrapartida, na percepção dos cooperados, ser fiel é comprar e vender na cooperativa. A perspectiva de lealdade presente no discurso dos dirigentes é mais ampla e envolve a dimensão cognitiva e afetiva, ao resgatar os princípios do cooperativismo como orientadores da relação entre cooperados e cooperativa (SIMIONI et al., 2009).

Isto significa dizer que não parece existir, de forma muito evidente, uma sustentação valorativa suficientemente sólida que possibilite ausência de contratos que orientem as transações. Do ponto de vista dos custos de transação, pode-se inferir que a ausência de um compromisso confiável entre as partes em torno do objeto comum pode comprometer a continuidade da relação, elevando os custos. (SIMIONI et al., p. 756).

Nesse sentido, Bialoskorski Neto (2002) advoga sobre a transformação da relação de transação de livre mercado, entre associado e a cooperativa, em uma relação contratual específica e obrigatória, como ocorre nas cooperativas da nova geração, que atrelam investimentos a direitos de entrega, inclusive em quantidade e qualidade definidos previamente. Neste caso, Bialoskorski Neto (2002) defende o uso de incentivos econômicos, visando dar maior estímulo à fidelidade do cooperado. Uma agregação de diferencial aos benefícios já gerados pela cooperativa poderá estimulá-lo a participar mais da cooperativa, participando das atividades propostas pela organização, comprar insumos e depositar a sua produção. Assim, quanto maior for à lealdade do cooperado, maior será a eficiência econômica do empreendimento coletivo. O mesmo conclui que o incentivo a fidelidade é obrigatório, pois o custo da não participação se torna maior na obrigatoriedade de entrega em quantidade e qualidade, o que não ocorre com os associados de cooperativas que mantém relações de livre mercado.

Nas palavras de Simioni et al. (2009, p. 759), "enquanto o foco dos dirigentes pretende uma modelação no comportamento do cooperado, no caso destes o foco é a modelação da cooperativa de acordo com os interesses individuais." Está ocorrendo um descompasso, onde os associados almejam benefícios imediatos oferecidos por empresas mercantis e pressionam suas entidades cooperativas para que proporcionem aos mesmos, vantagens cada vez maiores. Por outro lado, os dirigentes se veem acuados, tendo em vista que esse universo de vantagens imediatas pode acarretar problemas financeiros para as cooperativas, devido à elevação dos custos de transação.

A fidelidade de cooperados em cooperativas agropecuárias, no cenário atual do agronegócio brasileiro, passa em primeira estância, pela superação de um dilema: resgate dos valores cooperativistas de igualdade e ajuda mútua. Assim, se faz necessário que os interesses individuais sejam subordinados aos interesses da organização cooperativa.

Faz-se necessário que os cooperados percebam que as cooperativas são um meio para o seu desenvolvimento e de que sua existência está estritamente ligada à defesa dos interesses dos seus sócios (ROSALEM et al., 2009). O desafio é como trabalhar esses valores cooperativos dentro de uma sociedade competitiva e individualista como a nossa?

\footnotetext{
A deslealdade, na percepção dos dirigentes, ocorre nas situações em que o cooperado encontra-se com dificuldades financeiras, determinadas por atrasos de pagamento de seus financiamentos. Nestes casos, a comercialização da produção com a cooperativa implica no "sequestro" da receita em função dos débitos presentes, situação em que o cooperado busca outras opções para a solução de seus problemas. Outra causa de deslealdade é a ocorrência de preços melhores em outras empresas, seja para a compra de insumos ou para a comercialização de sua produção (SIMIONI et. al., 2009, p. 757).
}

O estudo de Simioni et al. (2009) concluiu que a maior parte das ocorrências de deslealdade, na compreensão dos cooperados, ocorre principalmente quando ele encontra preços mais competitivos em outros estabelecimentos.

Através da literatura consultada, principalmente as obras de Melesko (2012), Simioni et al. (2009), Bialoskorski Neto (2002) e Móglia et al. (2004), 
formulou-se hipóteses que poderão interferir na fidelização de associados em cooperativas agropecuárias. O quadro 2, no item metodologia, contém as hipóteses do problema.

\section{Metodologia}

Esse estudo foi realizado na Cooperativa Tritícola Sepeense Ltda- COTRISEL, mais precisamente na sua filial $\mathrm{n}^{\circ} 3$, situada no município de Restinga Sêca, Estado do Rio Grande do Sul. Tal unidade de negócio conta atualmente com 1.158 sócios ativos. Destes, 341 cooperados depositaram, parcial ou totalmente, sua produção de soja na cooperativa, na safra 2012/13. A pesquisa documental apontou ainda que, destes 341 cooperados, 244 possuíam DAP (Declaração de Aptidão ao PRONAF), perfazendo $71,55 \%$ dos depositantes de soja na cooperativa. Em contrapartida, 97 cooperados depositantes de soja, não tinham DAP, totalizando $28,45 \%$ dos produtores. A sigla PRONAF significa Programa Nacional de Fortalecimento da Agricultura Familiar. A COTRISEL, através de uma parceria com a Cooperativa Agropecuária Júlio de Castilhos - COTRIJUC remunera o associado produtor de soja e detentor da DAP, em R $\$ 1,00 /$ saca de $60 \mathrm{~kg}$, além do preço de tabela. Esse benefício começou a vigorar na safra 2012/13 e já apresentou reflexos positivos no volume de recebimento da cooperativa, tendo em vista que a maioria dos produtores de soja do município e que depositam na cooperativa, são pequenos produtores.

O método científico assume grande importância em pesquisas acadêmicas, permitindo maior aceitação dos resultados das investigações e legitimando o conhecimento adquirido empiricamente (CAMPOMAR, 1991).

Metodologicamente, utilizamos o método qualitativo, onde saímos a campo para investigar o problema de pesquisa, buscando-se qualificar os motivos que levaram os cooperados a depositar sua produção de soja na cooperativa. Dentre esses métodos qualitativos, o estudo de caso tem grande relevância.

No entendimento de Gil (2010), o estudo de caso é caracterizado pelo estudo profundo e exaustivo de um ou mais objetos, de modo que permita um conhecimento amplo e detalhado dos fatos. Para Yin (2005, p. 32), "o estudo de caso é um estudo empírico que investiga um fenômeno atual dentro de seu contexto de realidade, quando as fronteiras entre o fenômeno e o contexto não são claramente definidas e no qual são utilizadas várias fontes de evidência".

O presente estudo consiste em uma pesquisa aplicada (bibliográfica, documental e direta), de caráter exploratório, visando gerar informações de aplicação prática a respeito da fidelidade dos cooperados da COTRISEL. De modo geral, o estudo abrange todos os elementos do caso. Foi realizada uma revisão na literatura, através de livros, artigos científicos, dissertações e teses.

Segundo Gil (2010, p. 27), "as pesquisas exploratórias são desenvolvidas com objetivo de proporcionar visão geral, de tipo aproximativo, acerca do fato". As pesquisas exploratórias são conduzidas através de levantamento bibliográfico e documental, através de análise de conteúdo, questionário não padronizado e estudo de caso.

Quadro 1 - Variáveis utilizadas, foco de análise para a verificação do grau de relevância sobre a fidelidade dos cooperados da COTRISEL e $\mathrm{n}^{\circ}$ de proposições estudadas.

\begin{tabular}{|l|l|l|l|}
\hline $\mathbf{N}^{\circ}$ & \multicolumn{1}{|c|}{ Variáveis } & \multicolumn{1}{|c|}{ Hipóteses } & \multicolumn{1}{|c|}{$\begin{array}{c}\mathbf{N}^{\circ} \text { de proposições } \\
\text { estudadas }\end{array}$} \\
\hline 01 & $\begin{array}{l}\text { A Confiança, a credibili- } \\
\text { dade e honestidade da } \\
\text { cooperativa. }\end{array}$ & $\begin{array}{l}\text { Compromisso em fornecer insumos e receber } \\
\text { a produção do cooperado, bem como a pon- } \\
\text { tualidade nos pagamentos. } \\
\text { Nível de confiança estabelecida entre o asso- } \\
\text { ciado e os dirigentes diretamente ligados a } \\
\text { ele. }\end{array}$ & $\begin{array}{l}\text { Proposições 01 e } \\
02 .\end{array}$ \\
\hline 02 & Marketing & $\begin{array}{l}\text { Investimento em marketing voltado para seu } \\
\text { cooperado, demonstrando os benefícios que a } \\
\text { COTRISEL pode proporcionar. }\end{array}$ & Proposição 03. \\
\hline
\end{tabular}




\begin{tabular}{|c|c|c|c|}
\hline \multicolumn{4}{|c|}{ Continuação } \\
\hline 03 & Preço & $\begin{array}{l}\text { Preços pagos aos cooperados na comerciali- } \\
\text { zação da soja e preço dos insumos. }\end{array}$ & $\begin{array}{l}\text { Proposições 04, 05, } \\
06 \text { e } 07 .\end{array}$ \\
\hline 04 & $\begin{array}{l}\text { Descontos / Quebra técni- } \\
\text { ca }\end{array}$ & $\begin{array}{l}\text { Influência dos descontos/quebra técnica na } \\
\text { fidelidade de cooperados. }\end{array}$ & $\begin{array}{l}\text { Proposições } 08 \text { e } \\
09 .\end{array}$ \\
\hline 05 & Incentivos econômicos & $\begin{array}{l}\text { Concessão de incentivos econômicos para } \\
\text { maior fidelização dos cooperados. }\end{array}$ & Proposição 10. \\
\hline 06 & Assistência Técnica & $\begin{array}{l}\text { O atendimento personalizado do cooperado } \\
\text { influência na sua fidelidade para com a CO- } \\
\text { TRISEL? }\end{array}$ & Proposição 11. \\
\hline 07 & Estrutura de Recebimento & $\begin{array}{l}\text { O serviço de armazenagem e de recebimento } \\
\text { da cooperativa tem interferido na fidelidade } \\
\text { dos cooperados? }\end{array}$ & $\begin{array}{l}\text { Proposições } 12 \text { e } \\
13 .\end{array}$ \\
\hline 08 & Endividamento & $\begin{array}{l}\text { Verificar se o endividamento do cooperado } \\
\text { aumenta sua infidelidade para com a coope- } \\
\text { rativa. }\end{array}$ & Proposição 14. \\
\hline 09 & Contratos de troca-troca & $\begin{array}{l}\text { A prática de contratos de troca-troca traz } \\
\text { benefícios aos cooperados e aumenta o rece- } \\
\text { bimento de grãos pela cooperativa? }\end{array}$ & Proposição 15. \\
\hline 10 & Afinidade e hábito & $\begin{array}{l}\text { Hábito de depositar na cooperativa ou afini- } \\
\text { dade com o concorrente. }\end{array}$ & $\begin{array}{l}\text { Proposições } 16 \text { e } \\
17 .\end{array}$ \\
\hline 11 & Prazo & $\begin{array}{l}\text { O fornecimento de insumos com prazo safra, } \\
\text { afeta a fidelidade dos cooperados? }\end{array}$ & $\begin{array}{l}\text { Proposições } 18 \text { e } \\
19 .\end{array}$ \\
\hline 12 & Praça & $\begin{array}{l}\text { A localização do armazém da cooperativa } \\
\text { está interferindo na fidelidade? }\end{array}$ & $\begin{array}{l}\text { Proposições } 20 \text { e } \\
21 .\end{array}$ \\
\hline 13 & Distribuições das Sobras & $\begin{array}{l}\text { A devolução parcial das sobras líquidas inter- } \\
\text { fere na fidelidade? }\end{array}$ & Proposição 22. \\
\hline
\end{tabular}

Fonte: Adaptado de Bialoskorski Neto (2002); Melesko (2012); Móglia et al. (2004) e Simioni et. al (2009).

A pesquisa bibliográfica é desenvolvida a partir de material já elaborado, constituído de livros, artigos científicos, dissertações e teses (Gil, 2010). Ainda, permite ao investigador a cobertura de um número maior de fenômenos, tendo em vista o que poderia ser investigado diretamente.

Esse estudo de caso se valeu da pesquisa bibliográfica, com intuito de identificar os fatores interferentes na fidelidade dos cooperados da COTRISEL.
Desse modo, se constituído nas hipóteses do problema de pesquisa, descritas no Quadro 1.

Com intuito de mensurar percentualmente a fidelidade do associado, depositário de soja na COTRISEL, na safra 2012/13, criou-se um parâmetro de classificação da fidelidade, conforme descrito no Quadro 2.

Quadro 2 - Parâmetro de classificação da fidelidade dos cooperados da COTRISEL.

\begin{tabular}{|c|c|c|c|}
\hline \multicolumn{4}{|c|}{ Percentual de fidelidade na entrega de soja na safra 2012/13 } \\
\hline Até 25,0\% & De 25,01\% a 50,0\% & De 50,01\% a 75,0\% & Acima de 75,0\% \\
\hline Infiel (I) & Pouco Fiel (PF) & Moderadamente Fiel (MF) & Fiel (F) \\
\hline
\end{tabular}

Fonte: Autores da pesquisa.

A cooperativa adota atualmente seu próprio critério de fidelidade, onde se considera cliente fiel àquele que deposita $100 \%$ da sua produção na cooperativa. A este, quando ela vende insumos para sua 
produção agrícola, concede desconto de 4\%. No entanto, esse critério tem ocasionado alguns desgastes na relação cooperado $\mathrm{x}$ cooperativa. Para fins de estudo, seguiremos a classificação definida no Quadro 2. Através de uma investigação detalhada sobre área plantada com soja na última safra, média de produtividade obtida e entrega efetiva na cooperativa conseguiu-se mensurar com exatidão o percentual de fidelidade de cada cooperante.

A fim de verificar a relevância das variáveis interferentes na fidelidade dos cooperados, num terceiro momento, realizou-se uma pesquisa direta ou de campo, por meio de um questionário estruturado com algumas questões abertas e fechadas. Tal instrumento de pesquisa foi aplicado aos cooperados, produtores de soja que depositaram parcial ou to- talmente sua produção na cooperativa, na safra agrícola 2012/13.

Questionário é a técnica de investigação composta por um conjunto de questões que são submetidas a pessoas com o propósito de obter informações sobre conhecimentos, crenças, sentimentos, valores, interesses, expectativas, aspirações, temores, comportamento presente ou passado, etc. (GIL, 2010, p. 121).

Segundo Gil (2010), nos questionários estruturados, se estabelece uma relação fixa de perguntas, cuja ordem e redação permanecem invariáveis, para todos os respondentes.

O modelo de avaliação propôs escala de opiniões sobre as afirmativas propostas, conforme descrito no Quadro 3.

Quadro 3 - Modelo de avaliação com escala de opiniões.

\begin{tabular}{|c|c|c|c|c|}
\hline \multicolumn{5}{|c|}{ Escala de opiniões } \\
\hline $\begin{array}{c}\text { Sem Opinião } \\
\text { (SO) }\end{array}$ & $\begin{array}{c}\text { Discordo Total- } \\
\text { mente (DT) }\end{array}$ & $\begin{array}{c}\text { Discordo Parci- } \\
\text { almente (DP) }\end{array}$ & $\begin{array}{c}\text { Concordo Parci- } \\
\text { almente (CP) }\end{array}$ & $\begin{array}{c}\text { Concordo Total- } \\
\text { mente (CT) }\end{array}$ \\
\hline
\end{tabular}

Fonte: Adaptado de Likert (1976, p. 212 apud Gil, 2010, p. 144).

Foi realizada amostragem não probabilística por cotas, onde, em primeiro passo, classificou-se a população de depositantes em "associado com DAP" e "associado sem DAP". Num segundo momento, através da pesquisa documental, fixou-se o número de indivíduos de cada classe que responderam os questionários, ou seja, 69,4\% de "Associado com DAP" e 30,6\% de "Associado sem DAP". Posteriormente, os indivíduos foram selecionados de acordo com o maior volume de soja depositado na cooperativa, seguido da disponibilidade e acessibilidade do cooperante em responder o questionário.

Resumidamente, na coleta de dados e informações, utilizou-se como técnicas de pesquisa a aplicação de questionário estruturado junto aos cooperados, a análise de documentos e material bibliográfico.

Dessa maneira, responderam os questionários, 25 "associados com DAP" e 11 "associados sem DAP", totalizando 36 cooperados, ou seja, 10,6\% da população inicial que era de 341 cooperados depositantes de soja.

Foi realizada análise estatística descritiva percentual dos dados obtidos, utilizando como subsídio o referencial teórico.

\section{Resultados e Discussões}

Analisando o perfil dos respondentes verificouse que a maioria pertence ao sexo masculino, com faixa etária entre 41 a 60 anos, descendentes de imigrantes italianos, casados, com ensino fundamental completo ou incompleto, com mais de 25 anos de vivência em cooperativismo, cultivam soja e arroz irrigado, com área média de plantio de soja entre 20,01 a 50,0 hectares, e produtividade média na safra 2012/13 entre 40,01 a 50,0 sacas/hectare. Ainda, a maioria os entrevistados possuem DAP, cultiva soja em terras arrendadas, sempre participam das reuniões de núcleo e não ocupam cargos de gestão.

Através de uma questão aberta, os associados foram consultados sobre o que significa "fidelidade para com a cooperativa".

A maioria dos respondentes $(33,3 \%)$ revelou que fidelidade para com a cooperativa significa "depositar a produção na cooperativa". Para 25\%, "comprar os insumos e depositar a produção", outros 19,4\% definiram fidelidade como sendo "comprar os insumos e depositar a produção com frequência", "trabalhar com a cooperativa acima de tudo, independente de quaisquer erros e/ou acertos" é a opinião de $11,1 \%$ dos cooperados; para 2,8\% dos associados entrevistados, fidelidade "significa uma rela- 
ção em que a cooperativa tenha preferência nas transações comerciais, desde que pratique preços e condições iguais ou melhores que as oferecidas pelo concorrente"; outros 2,8\% conceituaram fidelidade como uma "política de preços e ajuda aos cooperados", "uma relação de parceria, onde o cooperado compra os insumos e deposita sua produção na cooperativa" são a opinião de $2,8 \%$, "depositar toda produção e comprar boa parte dos insumos na cooperativa" outros $2,8 \%$, e por fim, $2,8 \%$ corroboram com a opinião que fidelidade é "uma relação baseada em vantagens para ambos".

Simioni et al. (2009), em estudos com uma cooperativa agropecuária, revelou que o conceito de fidelidade para os dirigentes da cooperativa é bem mais amplo quando comparado com o discurso dos cooperados. Para os dirigentes, cooperado fiel é aquele que comercializa toda sua produção com a cooperativa; participam das reuniões, assembleias e eventos; confia e defende a cooperativa; cumpre seus deveres e exige seus direitos, conforme o estatuto; e valoriza a cooperativa. Em contrapartida, na percepção dos cooperados, ser fiel é comprar e vender na cooperativa.

Os resultados obtidos neste estudo são semelhantes aos obtidos por Simioni et al. (2009), pois 91,6\% dos cooperados entrevistados apresentaram conceito de fidelidade similar, isto é, comprar os insumos e depositar a produção.

Com auxílio de proposições abertas, investigouse qual a área plantada pelo cooperado com soja na safra 2012/13, qual foi sua média de produtividade obtida na referida safra e por último, qual foi o volume de soja (sacas) depositada na cooperativa. Assim sendo, conseguiu-se mensurar com exatidão o percentual de fidelidade de cada cooperante.

Com base nos resultados obtidos, verificou-se, de maneira geral, que $63,9 \%$ dos cooperados entrevistados foram fiéis a cooperativa quanto à entrega de soja, $16,7 \%$ foram moderadamente fiéis, $11,1 \%$ foram pouco fiéis e por fim, 8,3\% foram infiéis.

Outros resultados permitiram constatar que $68 \%$ dos cooperados entrevistados foram fiéis quanto à entrega de soja, $20 \%$ foram moderadamente fiéis, $4 \%$ foram pouco fiéis e por fim, $8 \%$ foram infiéis.

O estudo apontou que $88 \%$ dos associados com DAP foram moderadamente fiéis a fiéis com a cooperativa, no que se refere à entrega de soja na safra 2012/13. Em contrapartida, somente $63,6 \%$ dos associados sem DAP foram moderadamente fiéis a fiéis. Percebeu-se, portanto, uma maior fidelidade dos pequenos produtores em comparação com os grandes produtores de soja, no município de Restinga Sêca-RS.

Com intuito de apontar quais os principais motivos que levaram os associados da COTRISEL Unidade de Restinga Sêca/RS, a entregar sua produção de soja na cooperativa, na safra 2012/13. Avaliou-se 13 fatores condicionantes de fidelidade, cujos resultados estão descritos no Quadro 4.

A afirmativa um analisou se a confiança, a honestidade e a Credibilidade da COTRISEL, é fator decisivo, na hora do associado entregar sua produção de soja. 91,3\% dos cooperados entrevistados concordam totalmente com esta afirmativa, e outros $8,7 \%$ concordam parcialmente.

A afirmativa dois verificou se a pontualidade nos pagamentos pela cooperativa é fator preponderante na hora do cooperado depositar sua soja. Assim, $91,3 \%$ concordaram totalmente e outros $8,7 \%$ concordaram parcialmente com esta afirmativa.

É possível afirmar que a confiança, a credibilidade, a honestidade, a segurança e a pontualidade nos pagamentos são importantes valores cooperativistas, reconhecidos pelo seu quadro associativo, constituindo-se num diferencial competitivo desta.

$\mathrm{O}$ estudo apontou que o principal fator que levaram os cooperados a depositar a soja na cooperativa, refere-se à confiança, honestidade e a credibilidade da cooperativa. A credibilidade está relacionada com a pontualidade nos pagamentos. Esse resultado está de acordo com aquele obtido por Melesko (2012), que em seu estudo sobre fidelidade e lealdade com uma cooperativa agropecuária gaúcha, concluiu que o principal fator condicionante para a lealdade dos associados está relacionado com a confiança e a credibilidade da cooperativa.

Simioni et al. (2009), trabalhando com cooperativas agropecuárias, de infra-estrutura, de serviços e de crédito, nas regiões oeste e planalto sul Catarinense, e região de Campinas (SP) concluíram que o fator confiança na cooperativa é de fundamental para manutenção da lealdade.

A afirmativa três avaliou se a cooperativa necessita investir mais na área de marketing, principalmente voltado para o seu cooperado, demonstrando melhor os benefícios que pode proporcioná-lo. Dessa forma, o seu comprometimento para com a cooperativa aumentaria, depositando ainda mais sua produção de soja. 
Quadro 4 - Nível de concordância dos cooperados em relação às afirmativas propostas.

\begin{tabular}{|c|c|c|c|c|c|c|c|}
\hline \multirow[t]{2}{*}{$\mathbf{N}^{\circ}$} & \multirow[t]{2}{*}{ Afirmativas } & \multirow[t]{2}{*}{ Variáveis } & \multicolumn{5}{|c|}{ Avaliação Percentual } \\
\hline & & & CT & $\mathbf{C P}$ & DP & DT & SO \\
\hline 01 & $\begin{array}{l}\text { A confiança, a honestidade e a Credibili- } \\
\text { dade da COTRISEL é fator decisivo, na } \\
\text { hora de entregar minha produção de soja } \\
\text { nesta cooperativa. }\end{array}$ & $\begin{array}{l}\text { A confiança, } \\
\text { a honestida- } \\
\text { de e a Credi- } \\
\text { bilidade. }\end{array}$ & 91,7 & 8,3 & 0,0 & 0,0 & 0,0 \\
\hline 02 & $\begin{array}{l}\text { A pontualidade no pagamento, por parte da } \\
\text { cooperativa, é fator preponderante, quando } \\
\text { decido entregar minha produção de soja. }\end{array}$ & $\begin{array}{l}\text { A confiança, } \\
\text { a honestida- } \\
\text { de e a Credi- } \\
\text { bilidade. }\end{array}$ & 91,7 & 8,3 & 0,0 & 0,0 & 0,0 \\
\hline 03 & $\begin{array}{l}\text { O uso de incentivos econômicos (um bô- } \\
\text { nus a mais sobre o preço de tabela, para } \\
\text { aquele associado que depositar } 100 \% \text { da } \\
\text { produção de soja na cooperativa) aumenta- } \\
\text { ria o comprometimento deste, fazendo } \\
\text { com que entregasse totalmente sua produ- } \\
\text { ção. }\end{array}$ & $\begin{array}{l}\text { Incentivos } \\
\text { econômicos } \\
\text { a fidelidade. }\end{array}$ & 86,1 & 13,9 & 0,0 & 0,0 & 0,0 \\
\hline 04 & $\begin{array}{l}\text { O serviço de armazenagem da produção } \\
\text { me deixa satisfeito. }\end{array}$ & $\begin{array}{l}\text { Estrutura de } \\
\text { armazena- } \\
\text { gem da soja. }\end{array}$ & 80,6 & 13,9 & 2,8 & 0,0 & 2,8 \\
\hline 05 & $\begin{array}{l}\text { Um atendimento personalizado, por parte } \\
\text { da assistência técnica, durante todo o ciclo } \\
\text { da cultura, planejando as atividades (ma- } \\
\text { nejo da área, aquisição de insumos, aduba- } \\
\text { ção básica e de cobertura, tratos culturais e } \\
\text { colheita) aumenta o comprometimento dos } \\
\text { associados para com a cooperativa. }\end{array}$ & $\begin{array}{l}\text { Assistência } \\
\text { técnica. }\end{array}$ & 80,6 & 11,1 & 5,6 & 2,8 & 0,0 \\
\hline 06 & $\begin{array}{l}\text { O fornecimento de insumos (adubos, se- } \\
\text { mentes, diesel, herbicidas, inseticidas, } \\
\text { fungicidas, entre outros) com prazo de } \\
\text { pagamento para safra, é um fator impor- } \\
\text { tante, tendo em vista a fidelidade dos coo- } \\
\text { perados. }\end{array}$ & $\begin{array}{l}\text { Prazo de } \\
\text { pagamento } \\
\text { dos insumos. }\end{array}$ & 77,8 & 19,4 & 2,8 & 0,0 & 0,0 \\
\hline 07 & $\begin{array}{l}\text { Tenho por hábito entregar minha produção } \\
\text { na COTRISEL. }\end{array}$ & $\begin{array}{l}\text { Afinidade } \\
\text { com a coope- } \\
\text { rativa. }\end{array}$ & 72,2 & 22,2 & 2,8 & 0,0 & 2,8 \\
\hline 08 & $\begin{array}{l}\text { A devolução parcial das sobras líquidas } \\
(25 \%) \text {, após cada exercício social, contri- } \\
\text { bui para a fidelidade dos associados. }\end{array}$ & $\begin{array}{l}\text { A distribui- } \\
\text { ção das so- } \\
\text { bras líquidas. }\end{array}$ & 63,9 & 30,6 & 5,6 & 0,0 & 0,0 \\
\hline 09 & $\begin{array}{l}\text { Uma mudança nos padrões de classifica- } \\
\text { ção da soja quando do recebimento (des- } \\
\text { contos de umidade e de impurezas) faria } \\
\text { com que eu entregasse mais este cereal } \\
\text { para a COTRISEL. }\end{array}$ & $\begin{array}{l}\text { Descontos / } \\
\text { Quebra téc- } \\
\text { nica. }\end{array}$ & 61,1 & 16,7 & 13,9 & 8,3 & 0,0 \\
\hline 09 & $\begin{array}{l}\text { Uma mudança nos padrões de classifica- } \\
\text { ção da soja quando do recebimento (des- } \\
\text { contos de umidade e de impurezas) faria } \\
\text { com que eu entregasse mais este cereal } \\
\text { para a COTRISEL. }\end{array}$ & $\begin{array}{l}\text { Descontos / } \\
\text { Quebra téc- } \\
\text { nica. }\end{array}$ & 61,1 & 16,7 & 13,9 & 8,3 & 0,0 \\
\hline
\end{tabular}




\begin{tabular}{|c|c|c|c|c|c|c|c|}
\hline \multicolumn{8}{|c|}{ Continuação } \\
\hline \multirow{2}{*}{$\mathbf{N}^{\circ}$} & \multirow[t]{2}{*}{ Afirmativas } & \multirow[t]{2}{*}{ Variáveis } & \multicolumn{5}{|c|}{ Avaliação Percentual } \\
\hline & & & CT & $\mathbf{C P}$ & DP & DT & SO \\
\hline 10 & $\begin{array}{l}\text { A prática de contratos de troca-troca } \\
\text { (grãos por insumos), efetuado pela coope- } \\
\text { rativa, trás benefícios aos cooperados. } \\
\text { Portanto, essa prática aumenta a entrega de } \\
\text { soja na cooperativa. }\end{array}$ & $\begin{array}{l}\text { Contratos de } \\
\text { troca-troca. }\end{array}$ & 58,3 & 30,6 & 2,8 & 0,0 & 8,3 \\
\hline 11 & $\begin{array}{l}\text { O fornecimento de insumos necessários } \\
\text { para a produção de soja, com preços com- } \\
\text { petitivos no mercado (igual ou inferior aos } \\
\text { da concorrência), influencia a fidelidade } \\
\text { dos cooperados, fazendo com que entregue } \\
\text { a maior parte de sua produção de soja. }\end{array}$ & $\begin{array}{l}\text { Preço dos } \\
\text { insumos. }\end{array}$ & 55,6 & 27,8 & 8,3 & 5,6 & 2,8 \\
\hline 12 & $\begin{array}{l}\text { Se o preço da soja for superior no concor- } \\
\text { rente, mesmo assim entrego minha produ- } \\
\text { ção na COTRISEL, pois não seria certo } \\
\text { abandonar minha cooperativa nesse mo- } \\
\text { mento. }\end{array}$ & $\begin{array}{l}\text { Preço pago } \\
\text { pela soja. }\end{array}$ & 52,8 & 25,0 & 13,9 & 8,3 & 0,0 \\
\hline 13 & $\begin{array}{l}\text { O preço pago pela cooperativa, quando } \\
\text { comercializo a soja, atende minha expecta- } \\
\text { tiva. }\end{array}$ & $\begin{array}{l}\text { Preço pago } \\
\text { pela soja. }\end{array}$ & 44,4 & 41,7 & 11,1 & 2,8 & 0,0 \\
\hline 14 & $\begin{array}{l}\text { A cooperativa necessita investir mais em } \\
\text { marketing voltado para seu cooperado, } \\
\text { demonstrando os benefícios que a CO- } \\
\text { TRISEL pode proporcionar. Dessa forma, } \\
\text { o seu comprometimento para com a coope- } \\
\text { rativa aumentaria, depositando ainda mais } \\
\text { sua produção de soja. }\end{array}$ & Marketing & 44,4 & 41,7 & 8,3 & 5,6 & 0,0 \\
\hline 15 & $\begin{array}{l}\text { Uma maior agilidade no recebimento e } \\
\text { descarga da soja faria com que os coope- } \\
\text { rados entregassem mais este cereal na } \\
\text { COTRISEL. }\end{array}$ & $\begin{array}{l}\text { Estrutura de } \\
\text { recebimento } \\
\text { da soja. }\end{array}$ & 44,4 & 38,9 & 11,1 & 2,8 & 2,8 \\
\hline 16 & $\begin{array}{l}\text { Os descontos praticados pela cooperativa } \\
\text { (quebra técnica), no momento da entrega } \\
\text { da produção de soja, afeta minha fidelida- } \\
\text { de para com a cooperativa. }\end{array}$ & $\begin{array}{l}\text { Descontos / } \\
\text { Quebra téc- } \\
\text { nica. }\end{array}$ & 44,4 & 25,0 & 11,1 & 16,7 & 2,8 \\
\hline 17 & $\begin{array}{l}\text { Uma ajuda no frete seria indispensável, } \\
\text { pois minha lavoura de soja fica mais perto } \\
\text { do concorrente e por consequência, mais } \\
\text { distante do armazém da COTRISEL. }\end{array}$ & $\begin{array}{l}\text { Praça de } \\
\text { recebimento } \\
\text { da soja. }\end{array}$ & 27,8 & 30,6 & 8,3 & 13,9 & 19,4 \\
\hline 18 & $\begin{array}{l}\text { Entrego minha produção de soja na coope- } \\
\text { rativa porque está localizada próxima a } \\
\text { minha lavoura. }\end{array}$ & $\begin{array}{l}\text { Praça de } \\
\text { recebimento } \\
\text { da soja. }\end{array}$ & 16,7 & 22,2 & 8,3 & 38,9 & 13,9 \\
\hline 19 & $\begin{array}{l}\text { Tenho afinidade com o concorrente, por } \\
\text { isso não entrego parcial ou totalmente, } \\
\text { minha produção na cooperativa. }\end{array}$ & Afinidade. & 13,9 & 11,1 & 5,6 & 41,7 & 27,8 \\
\hline 19 & $\begin{array}{l}\text { Tenho afinidade com o concorrente, por } \\
\text { isso não entrego parcial ou totalmente, } \\
\text { minha produção na cooperativa. }\end{array}$ & Afinidade. & 13,9 & 11,1 & 5,6 & 41,7 & 27,8 \\
\hline 20 & $\begin{array}{l}\text { O preço pago pela cooperativa, quando } \\
\text { comercializo a soja, me propicia vantagens } \\
\text { econômicas, influenciando positivamente } \\
\text { minha decisão de entregar toda produção } \\
\text { de soja na cooperativa. }\end{array}$ & $\begin{array}{l}\text { Preço pago } \\
\text { pela soja. }\end{array}$ & 8,3 & 30,6 & 19,4 & 41,7 & 0,0 \\
\hline
\end{tabular}




\begin{tabular}{|c|c|c|c|c|c|c|c|}
\hline \multirow[t]{2}{*}{$\mathbf{N}^{\circ}$} & \multirow[t]{2}{*}{ Afirmativas } & \multirow[t]{2}{*}{ Variáveis } & \multicolumn{5}{|c|}{ Avaliação Percentual } \\
\hline & & & CT & $\mathbf{C P}$ & DP & DT & SO \\
\hline 21 & $\begin{array}{l}\text { Fui financiado pelo concorrente e assim } \\
\text { devo entregar minha produção de soja a } \\
\text { ele. }\end{array}$ & $\begin{array}{l}\text { Prazo de } \\
\text { pagamento } \\
\text { dos insumos. }\end{array}$ & 8,3 & 2,8 & 5,6 & 55,6 & 27,8 \\
\hline 22 & $\begin{array}{l}\text { Tenho dívidas na COTRISEL. Se eu en- } \\
\text { tregar parte ou toda minha produção de } \\
\text { soja na cooperativa, a mesma ficará "blo- } \\
\text { queada" até o pagamento da minha dívida. } \\
\text { Dessa forma, não tenho depositado na } \\
\text { cooperativa. }\end{array}$ & $\begin{array}{l}\text { Endivida- } \\
\text { mento }\end{array}$ & 5,6 & 5,6 & 2,8 & 44,4 & 41,7 \\
\hline
\end{tabular}

Legenda: $\mathrm{CT}=$ Concordo Totalmente $; \mathrm{CP}=$ Concordo Parcialmente DT $=$ Discordo Totalmente DP $=$ Discordo Parcialmente; $\mathrm{SO}=$ Sem Opinião.

Fonte: Dados da pesquisa.

Os entrevistados revelaram haver necessidade de investimento em marketing. Concordaram totalmente com essa afirmativa, $44,4 \%$ dos respondentes. Outros $41,7 \%$ concordaram parcialmente. Esse marketing refere-se a uma presença maior da cooperativa na comunidade do interior, participando das festividades. Também se relaciona com as visitas técnicas na propriedade (assistência técnica), ligar para o cooperado quando se tem uma oportunidade de negócio diferenciada, brindes (uma jaqueta, por exemplo) com intuito de promover o nome da cooperativa. Assim sendo, conclui-se que os associados percebem a falta de uma presença mais significativa da cooperativa junto às comunidades.

A afirmativa quatro analisou se o preço pago pela cooperativa atende as expectativas de seu cooperado. A pesquisa revelou que $44,4 \%$ concordam totalmente, isto é, o preço pago pela soja atende a expectativa. Outros 41,7\% concordam parcialmente com essa afirmativa. Discordam parcial ou totalmente, $13,9 \%$.

A afirmativa cinco avaliou se o preço pago pela cooperativa, quando o associado comercializa sua soja, lhe propicia vantagens econômicas e influencia positivamente sua decisão de entregar toda produção de soja na cooperativa.

A pesquisa revelou divergência de opiniões quanto a essa afirmativa. Apenas 50\% concordam total ou parcialmente, com a afirmativa de que o preço pago pela cooperativa é um fator importante quando da decisão de entregar a soja na COTRISEL. Outros $50 \%$ discordam parcial ou totalmente com essa afirmativa.

Fazendo um paralelo entre as afirmativas quatro e cinco, conclui-se que apesar de o preço pago pela cooperativa atender as expectativas dos cooperados (afirmativa quatro), percebeu-se nas entrevistas que o preço não é o grande motivador para que os associados depositem sua soja na cooperativa. Os fatores confiança, credibilidade, honestidade e segurança possuem influência bem mais significativa do que a variável preço. Alguns cooperados fizeram algumas considerações sobre a afirmativa cinco, a saber: "deposito independentemente de preço", "se depositar a soja, quando necessitar de financiamento para safra, a cooperativa ajuda", "deposito pela segurança que a cooperativa me propicia", "uma solução seria a cooperativa diferenciar preço, porém como fica o pequeno produtor. Não concordo muito com isso".

De acordo com os estudos de Simioni et al. (2009), a maior parte das ocorrências de deslealdade, na compreensão dos cooperados, ocorre principalmente quando ele encontra preços mais competitivos em outros estabelecimentos. Assim sendo, a cooperativa necessita estar atenta ao mercado, com preços competitivos e propiciando vantagens econômicas aos cooperados, sempre com objetivo de aumentar o volume de recebimento de soja.

A afirmativa seis verificou se o preço da soja for superior no concorrente, mesmo assim o cooperado entrega sua produção na COTRISEL, pois não seria certo abandoná-la nesse momento. A pesquisa apontou que $77,8 \%$ concordam parcial ou totalmente com a afirmativa de que, mesmo se o preço pago pela soja for superior no concorrente, não deixa de depositar na cooperativa, pois fatores como segurança, honestidade, pontualidade, confiança, vende quando quiser e a quantia que necessitar, contribui para esse resultado. Móglia (2004) advoga nesse 
sentido dizendo que o cooperado intitulado fiel não abandona sua cooperativa com facilidade, pois ele tem esperança que num futuro próximo, a situação se reverta.

O estudo revelou que $83,3 \%$ concordam parcial ou totalmente com a afirmativa sete, onde "o fornecimento de insumos com preços competitivos interfere na fidelidade do cooperado". Um dos respondentes fez a seguinte consideração: "a venda de insumos cria um vínculo que culmina com a entrega da produção" e, "se comprar de terceiros pode acabar não depositando sua soja na cooperativa". Com esse comentário percebe-se a importância desta variável. Esse resultado obtido pela pesquisa vai de encontro ao relatado por Melesko (2012), onde os bons preços dos produtos oferecidos pela cooperativa interferem positivamente na fidelidade dos cooperados.

A proposição oito averiguou se os descontos/quebra técnica praticada pela cooperativa no momento do recebimento da soja, afeta a fidelidade de seu cooperado. A pesquisa apontou que 69,4\% concordam parcial ou totalmente, que os descontos praticados pela cooperativa, no recebimento de soja, afetam a fidelidade de seu cooperado produtor de soja e depositante na cooperativa.

A proposição nove verificou se uma mudança nos padrões de classificação da soja quando do recebimento (descontos de umidade e de impurezas) faria com que o associado produtor de soja entregasse mais este cereal na COTRISEL. O resultado evidenciou que para $77,8 \%$ dos cooperados entrevistados, uma mudança nos padrões de impurezas (tolerância de $1 \%$ de impurezas) faria com que os cooperados depositassem mais soja na cooperativa. Os números revelaram que $61,1 \%$ concordam totalmente e $16,7 \%$ concordam parcialmente. Para $22,2 \%$, os padrões de determinação de umidade e de impurezas devem permanecer os mesmos, pois discordam total ou parcialmente, sobre uma possível mudança.

Assim sendo, os descontos praticados pela cooperativa na hora da entrega da produção é fator inibidor a lealdade do cooperado. Esse resultado vai de encontro ao resultado obtido por MELESKO (2012).

Um dos respondentes sugeriu que no ticket da balança, após pesar a tara do caminhão, deveria aparecer à quantidade de quebra técnica, em kilos, para que o produtor pudesse identificar facilmente $o$ quanto foi descontado. Alguns concorrentes no recebimento de soja agem dessa forma, emitindo tais informações no ticket.

A proposição dez abordou se o uso de incentivos econômicos a fidelidade dos cooperados. A afirmativa diz que o uso de incentivo econômico (um bônus a mais sobre o preço de tabela) para aquele associado que depositar toda sua produção na cooperativa, aumenta o seu comprometimento, levando-o a depositar integralmente sua produção na cooperativa. O resultado evidenciou que $86,1 \%$ dos cooperados entrevistados concordaram totalmente com o uso de incentivos econômicos a fidelidade e 13,9\% concordaram parcialmente. Portanto, $100 \%$ dos respondentes foram favoráveis, parcial ou totalmente, com a afirmativa em questão.

Esses resultados vão de encontro ao que foi descrito por Bialoskorski Neto (2002). Tal autor defende o uso de incentivos econômicos, visando dar maior estímulo à fidelidade do cooperado. Um "plus" a mais sobre o preço de tabela poderá estimular mais o cooperado, fazendo com que participe ativamente junto a cooperativa, comprando insumos, participando das reuniões e depositando integralmente sua produção.

Com a proposição onze, verificou-se a importância de um atendimento personalizado, por parte da assistência técnica, durante todo o ciclo da cultura, planejando as atividades (manejo da área, aquisição de insumos, adubação básica e de cobertura, tratos culturais e colheita) com relação ao aumento do comprometimento dos associados para com a cooperativa. A pesquisa revelou que $80,6 \%$ dos respondentes concordaram totalmente com importância de um atendimento personalizado, por parte da assistência técnica. Outros $11,1 \%$ concordaram parcialmente com tal afirmativa. Somente $8,3 \%$ discordaram parcial ou totalmente, com relação à importância da assistência técnica na fidelização dos associados.

O resultado obtido é similar ao relatado por Melesko (2012), onde o bom atendimento e a boa qualidade da assistência técnica contribuem para a lealdade dos associados. Alguns entrevistados relataram que seria importante para a cooperativa, ter um vendedor externo com o objetivo de vender e de entregar os insumos. Outros entrevistados relataram que é preciso melhorar os preços dos insumos comercializados pela cooperativa. 
Para Simioni et al. (2009), trabalhando com cooperativas agropecuárias, de infra-estrutura, de serviços e de crédito, nas regiões oeste e planalto sul Catarinense, e região de Campinas (SP) concluíram que na percepção dos cooperados a variável mais importante na manutenção da lealdade dos mesmos é atendimento ao cooperado.

Com a proposição doze, verificou-se o funcionamento do serviço de armazenagem da produção, no intuito de atender a necessidade do cooperado. Através da proposição treze, verificou-se a necessidade de uma maior agilidade no recebimento e descarga da soja, com intuito de aumentar a lealdade dos cooperados. Melesko (2012), em seu estudo, concluiu que a variável estrutura de recebimento interferiu positivamente na fidelidade dos cooperados.

Os resultados evidenciaram a necessidade de uma maior agilidade no recebimento e descarga da soja, pois $44,4 \%$ concordaram totalmente e $38,9 \%$ parcialmente, com a afirmativa proposta. O nível de discordância parcial ou totalmente foi de 13,9\%. Outros 2,8\% não opinaram nessa questão.

Mesmo concordando que o serviço de armazenagem da soja atende as expectativas, muitos entendem que uma agilidade na descarga é bem vinda, pois há muita pressão dos caminhoneiros na hora de transportar a produção. Assim sendo, é necessário um trabalho com os caminhoneiros, procurando demonstrar o empenho e a preocupação da cooperativa com o recebimento da safra de soja. Nas duas últimas safras, o recebimento da soja ocorreu de maneira normal, sem ocorrência de filas, contribuído para que essa variável não apresentasse um alto nível de concordância total. No entanto, não significa que a cooperativa deva despreocupar-se com o recebimento. É possível que em anos de elevada produtividade da soja, essa variável adquira ênfase ainda maior.

A proposição quatorze averiguou se o endividamento do cooperado para com a cooperativa está interferindo na sua fidelidade. Através da afirmativa: tenho dívidas na COTRISEL. Se eu entregar parte ou toda minha produção de soja na cooperativa, a mesma ficará "bloqueada" até o pagamento da minha dívida. Dessa forma, não tenho depositado na cooperativa. Os resultados mostraram que a grande maioria dos respondentes discordou parcial ou totalmente $(47,2 \%)$ ou não opinou nessa proposição $(41,7 \%)$. O nível de concordância parcial ou totalmente foi de apenas $11,2 \%$. Esse resultado reflete um baixo nível de endividamento dos cooperados para com a sua cooperativa, no município de Restinga Sêca-RS. Em cooperativas agropecuárias com um maior endividamento dos cooperados, essa variável pode adquirir maior significância.

A afirmativa quinze estudou a importância dos contratos de troca-troca, tendo em vista a entrega de soja por parte dos cooperados. A proposição diz: a prática de contratos de troca-troca (grão por insumos), efetuado pela cooperativa, trás benefícios aos cooperados e aumenta a entrega de soja na cooperativa. Os resultados comprovaram a importância dessa modalidade de contrato. O nível de concordância total foi de $58,3 \%$ e outros $30,6 \%$ concordaram parcialmente. Apenas $2,8 \%$ discordaram parcialmente com a afirmativa acima. Concluiu-se que a cooperativa, cada vez mais, deve investir nessa modalidade de contrato, propiciando vantagens para o associado.

A proposição dezesseis avaliou a afinidade do cooperado com o concorrente, como motivo de infidelidade para com sua cooperativa. Para essa proposição, a grande maioria dos entrevistados discordou totalmente $(41,7 \%)$ ou parcialmente $(5,6 \%)$. Outros 27,8\% não opinaram. Dessa forma, concluiu-se que a afinidade com o concorrente não é motivo substancialmente importante para a deslealdade dos cooperados produtores de soja, associados da cooperativa.

A proposição dezessete abordou o hábito de depositar a soja na COTRISEL, como fator de fidelidade do cooperado. Os resultados evidenciaram que $72,2 \%$ dos respondentes concordaram totalmente com a proposição e $22,2 \%$ concordaram parcialmente. O nível de discordância foi de apenas $2,8 \%$, sendo que outros $2,8 \%$ não opinaram.

Os resultados estão de acordo com Móglia et al. (2004) que apontaram o hábito de depositar a produção cooperativa como um fator importante para a manutenção da fidelidade dos cooperados.

A proposição dezoito avaliou a importância do financiamento do cooperado com prazo de pagamento para a safra (após a colheita da soja). Assim, a afirmativa dizia que o fornecimento de insumos (adubos, sementes, diesel, herbicidas, inseticidas, fungicidas, entre outros) com prazo de pagamento para safra, é um fator importante, tendo em vista a fidelidade dos cooperados. A COTRISEL, em sua unidade, no município de Restinga Sêca-RS, possui 
tradição no financiamento de cooperados, tendo trabalhado com um volume de R\$6.000.000,00/ano. Valor este, muitas vezes, superior ao volume emprestado por algumas instituições bancárias tradicionais. Simioni et al. (2009), trabalhando com cooperativas agropecuárias, de infra-estrutura, de serviços e de crédito, nas regiões oeste e planalto sul Catarinense, e região de Campinas (SP) concluíram que na percepção dos cooperados, o prazo de pagamento dos insumos e o crédito aos cooperados são variáveis importantes na manutenção da lealdade dos mesmos.

Os resultados evidenciaram a importância dessa variável. Dentre os respondentes, $77,8 \%$ concordaram totalmente e $19,4 \%$ parcialmente. Esse resultado vai de encontro ao descrito por Simioni et al. (2009). O nível de discordância parcial foi de apenas $2,8 \%$.

A proposição dezenove verificou a importância do financiamento do cooperado por outras cooperativas e/ou empresas mercantilistas concorrentes. Através da afirmativa "fui financiado pelo concorrente e assim devo entregar minha produção de soja a ele", conseguiu-se ter uma dimensão desta variável, tendo em vista a lealdade dos cooperados. Apenas $8,3 \%$ dos respondentes concordaram totalmente com essa afirmativa e outros $2,8 \%$ concordaram parcialmente. A grande maioria dos entrevistados discordou total $(55,6 \%)$ ou parcialmente $(5,6 \%)$ com a afirmativa proposta nesta questão. Dessa forma, concluiu-se que o nível de financiamento dos cooperados fora da COTRISEL é baixo. A cooperativa é uma das principais organizações financiadoras dos produtores rurais cooperativados. A deslealdade ocorre devido a fatores econômicos (preço da soja, muitas vezes, inferior ao do concorrente) e descontos/quebra técnica no recebimento da soja, mais especificamente a impurezas. Alguns concorrentes apresentam uma tolerância de $1 \%$ de impurezas no recebimento da soja, servindo muitas vezes, de atrativo aos cooperados da COTRISEL. Assim, alguns deixam de ser totalmente fieis a cooperativa. A COTRISEL está realizando internamente, alguns estudos com intuito de possibilitar ou não, essa tolerância de $1 \%$ de impurezas. Caso se confirme essa tolerância, a tendência natural é de que a fidelidade aumente gradativamente.

A proposição vinte, e vinte e um, avaliou se a localização do armazém da COTRISEL tem causado interferência significativa na fidelidade de seus co- operados, produtores de soja. A proposição vinte afirma que uma ajuda no frete seria indispensável, pois a lavoura de soja do cooperado situa-se mais perto do concorrente, quando comparado com a cooperativa. O resultado evidenciou que 58,3\% concordaram parcial ou totalmente com essa afirmativa. Outros $22,2 \%$ discordaram parcial ou totalmente e por fim, 19,4\% não opinaram.

Dentre os respondentes que concordaram com essa ajuda, um deles fez a seguinte ponderação: "poderá influenciar sim, visto que a GRANOL tem dado ajuda no frete para alguns produtores". Com esse resultado percebe-se que quaisquer incentivos econômicos possuem impacto positivo, tendo em vista que a grande maioria dos produtores prefere o benefício imediato. Móglia et al. (2004), em seus estudos com uma Cooperativa Agropecuária Mista da Região de Orlândia (CAROL), na safra 2001/02, concluíram que um dos principais motivos da infidelidade para com a cooperativa diz respeito a uma ajuda no frete por parte do concorrente, fazendo com que o associado da CAROL deixasse de ser totalmente fiel.

A proposição vinte e um tem como intuito entender se o cooperado deposita sua soja na COTRISEL porque está localizada mais próxima de sua lavoura ou há outras variáveis mais importantes.

Os resultados estão expressos no Quadro 4. Conclui-se que fato de a cooperativa estar mais próxima da lavoura do associado, tendo em vista o recebimento da soja, foi significativamente importante para apenas $16,7 \%$ dos entrevistados. Para $22,2 \%$, a importância foi parcial. Outros 47,2\% discordaram parcial ou totalmente com a afirmativa acima, fazendo ponderações como a seguinte: "se o restaurante é bom, mesmo que seja distante da minha casa, a gente da um jeito de ir almoçar". Nesse sentido, o que mais motiva o associado a depositar sua produção refere-se a confiança, a honestidade, a credibilidade, a pontualidade, boa estrutura de armazenagem, assistência técnica, Prazo de pagamento dos insumos (financiamento do cooperado), afinidade com a cooperativa, distribuição das sobras de acordo com o estatuto social e contratos de trocatroca.

A proposição vinte e dois averiguou se a devolução das sobras ( $25 \%$ das sobras líquidas), após cada exercício social, contribui para o incremento da fidelidade dos cooperados da COTRISEL. Para essa proposição, o nível de concordância total foi de 
$63,9 \%$ e concordância parcial foi de $30,6 \%$. Apenas $5,6 \%$ dos entrevistados discordaram parcialmente.

Os associados que concordaram com essa proposição, relataram que a devolução das sobras líquidas, de acordo com o estatuto, serve de estímulo ao cooperado, tendo em vista a sua fidelidade para com a cooperativa.

\section{Conclusão}

A infidelidade, principalmente em cooperativas agropecuárias, é um problema sério, e que compromete a situação econômica da cooperativa, podendo levá-la a dificuldades financeiras. As cooperativas agropecuárias estão inseridas em um ambiente altamente competitivo e mutável, exigindo maior comprometimento dos cooperados.

A literatura sugere diversas variáveis interferentes na fidelidade de cooperados. Este estudo buscou mensurar o grau de fidelidade dos cooperados e apontar os motivos que levaram os cooperados da COTRISEL, unidade de Restinga Sêca-RS, a depositarem sua produção de soja, na safra 2012/13.

Inicialmente, a pesquisa com os cooperados possibilitou uma identificação do perfil dos respondentes. A maioria pertence ao sexo masculino, com faixa etária entre 41 a 60 anos, descendentes de imigrantes italianos, casados, com ensino fundamental completo ou incompleto, com mais de 25 anos de vivência em cooperativismo, cultivam soja e arroz irrigado, com área média de plantio de soja entre 20,01 a 50,0 hectares, e produtividade média na safra 2012/13 entre 40,01 a 50,0 sacas/hectare. Ainda, a maioria os entrevistados possuem DAP, cultiva soja em terras arrendadas, sempre participam das reuniões de núcleo e não ocupam cargos de gestão.

A fidelidade, condição básica essencial do cooperativismo, foi analisada através de uma questão aberta, onde o cooperado entrevistado colou sua opinou sobre o termo. A grande maioria dos respondentes entendeu fidelidade como sendo comprar os insumos e depositar a produção de soja na cooperativa.

A pesquisa classificou o cooperante de acordo com sua fidelidade na entrega da produção de soja na cooperativa. Considerou-se cliente fiel àquele que depositou acima $75 \%$ da sua produção anual desta oleaginosa. Cliente moderadamente fiel, quem depositou entre $50,01 \%$ a $75 \%$ da produção anual. O associado que depositou entre $25,01 \%$ a $50,0 \%$ foi classificado como pouco fiel. Por fim, quem depositou abaixo de $25 \%$ foi denominado infiel.

O estudo revelou que $63,9 \%$ dos cooperados entrevistados foram fiéis à cooperativa quanto à entrega da soja, na safra 2012/13. Outros 16,7\% foram moderadamente fiéis, $11,1 \%$ foram pouco fiéis e por fim, $8,3 \%$ foram infiéis. Ainda, a pesquisa abordou a fidelidade dos associados com DAP e sem DAP, separadamente. Os resultados indicaram que $88 \%$ dos associados com DAP foram moderadamente fiéis a fiéis com a cooperativa. Em contrapartida, somente $63,6 \%$ dos associados sem DAP foram moderadamente fiéis a fiéis. Encontrou-se, portanto, uma maior fidelidade dos pequenos produtores em comparação com os grandes produtores de soja, no município de Restinga Sêca-RS.

$\mathrm{O}$ estudo mostrou que a confiança, a honestidade e a credibilidade da cooperativa, pontualidade nos pagamentos, estrutura de armazenagem, assistência técnica, prazo de pagamento dos insumos para safra (financiamento do cooperado), hábito de entregar a produção na cooperativa, distribuição das sobras líquidas conforme estatuto social e contratos de troca-troca (grão por insumos) foram os principais fatores que estimularam a fidelidade cooperados da COTRISEL, respectivamente.

Como fatores que desestimularam a fidelidade, citam-se os descontos praticados pela cooperativa na hora da entrega da produção de soja, o preço pago pela cooperativa não é muito atrativo (muitas vezes o cooperado encontra preços mais competitivos em outros estabelecimentos), e uma agilidade maior no recebimento e descarga da soja. As variáveis envolvendo financiamento do cooperado por outras empresas e dívidas com a cooperativa, como fator inibidor da lealdade, citados por outros pesquisadores, nesse estudo não logrou significância maior.

Ainda, o estudo abordou outras três variáveis que podem ser mais bem utilizadas pela cooperativa. Trata-se dos incentivos econômicos a fidelidade, marketing e ajuda no frete. $\mathrm{O}$ uso de incentivos econômicos visando promover a lealdade dos cooperados, defendido por Bialoskorski Neto (2002), apresentou nível de concordância total de $86,1 \%$ e parcial de $13,9 \%$. Sendo assim, as cooperativas agropecuárias devem fazer um estudo sobre a viabilidade de implantação desta prática. Em menor es- 
cala de importância que os incentivos econômicos, surgem o marketing voltado aos cooperados e ajuda no frete para aqueles associados que se situam mais distantes do armazém da cooperativa.

Finalmente, os objetivos do trabalho foram amplamente atingidos. O presente artigo procurou trazer algumas contribuições acerca do tema fidelidade em cooperativas agropecuárias. No entanto, o tema é de grande importância e o assunto não se esgota aqui, pois a realidade de cada cooperativa é um pouco distinta, havendo outras variáveis interferentes na fidelidade. Como sugestão para estudos futuros, recomenda-se avaliar a fidelidade dos jovens cooperados (faixa etária de 18 a 30 anos), pois se percebeu que essa faixa etária apresenta maior propensão a infidelidade.

\section{Referências}

BIALOSKORSKI NETO, S. (Org.) Trabalho III Workshop Internacional de Tendências do Cooperativismo - Cooperativas: Um Ensaio sobre Eficiência Econômica, Contratos e Fidelidade. Ribeirão Preto, ago. 2002. Disponível em:<http://www.fearp.usp.br/ sigbial/inserir_out 2002/Trabalhos\%20Apresentados/Contratos\%20 e\%20Fidelidade.pdf>. Acesso em: 10 out. 2013.

BORK, F. S. Caracterização da percepção dos associados na sua relação com a COOPAR - Cooperativa Mista de Pequenos Agricultores da Região Sul. São Lourenço do Sul, RS. 2011. Trabalho de conclusão submetido ao Curso de Graduação Tecnológico em Planejamento e Gestão para o desenvolvimento Rural - PLAGEDER, da Faculdade de Ciências Econômicas da UFRGS, como quesito parcial para obtenção do Título de Tecnólogo em Planejamento e Gestão para o Desenvolvimento Rural. 66p. Disponível em: <http://www.lume.ufrgs.br/bitstream/handle/101 83/38141/000821696.pdf?sequence $=1>$ Acesso em: 09 out. 2013.

CAMPOMAR, M. C. Do uso de "estudo de caso" em pesquisas para dissertações e teses em administração. Ver. De Administração: São Paulo, v. 26, n. 3, p. 95-97, jul./ago. 1991. Disponível em: $<$ http://www.pessoal.utfpr.edu.br/luizpepplow/di scipli-
nas/metodologia/O\%20uso\%20de\%20estudos\%2 0de\%20caso.pdf >. Acesso em: 24 jun. 2011.

COTRISEL - Cooperativa Tritícola Sepeense Ltda. Empresa. São Sepé-RS. Disponível em: $<$ http://www.cotrisel.com/empresa.php $>$. Acesso em: 25 jun. 2011.

FARIA, V. P. de. Produção e cooperativas de produtores de leite no Brasil. In: Seminário as Cooperativas e a Produção de Leite no Ano 2000, Belo Horizonte. Anais... Belo Horizonte: Organização das Cooperativas do Estado de Minas Gerais, 1995. p. 13-19 GIL, A. C. Métodos e técnicas de pesquisa social. 6. Ed. - 3. Reimpr. São Paulo: Atlas, 2010.

MELESKO, B. M. Fidelidade e lealdade: uma relação dos cooperados com sua cooperativa. Monografia apresentada ao Curso de Pós-Graduação lato sensu em Gestão de Cooperativas da UNIJUÍ - UNIVERSIDADE REGIONAL DO ESTADO DO RIO GRANDE DO SUL - DACECDEPARTAMENTO DE CIÊNCIAS ADMINISTRATIVAS, CONTÁBEIS, ECONÔMICAS E DA COMUNICAÇÃO. 2012. Disponível em: < http://bibliodigital.unijui.edu.br:8080/xmlui/bitst $\mathrm{ram} /$ handle/123456789/556/Bruno\%20Mateus\% 20Melesko.pdf?sequence $=1>$. Acesso em: 10 out. 2013.

MOGLIA, L. C.; PARADA JUNIOR, I.; BIALOSKORSKI NETO, S.; MARCHI, D. Fidelidade e reciprocidade do cooperado: o caso da CAROL. 2004.Disponível em: <http://www.sober.org.br/palestra/12/04P261.pd f>. Acesso em: 18 set. 2013.

OCB - Organização das Cooperativas Brasileiras. Apresentação Institucional 2012. Brasília. Disponível em: <http://www.ocb.org.br/site/cooperativismo/insti tucional.asp>. Acesso em: 24 jan. 2012.

OCB - Organização das Cooperativas Brasileiras. Ramos. Brasília. Disponível em: <http://www.ocb.org.br/site/ramos/estatisticas.as p>. Acesso em: 24 jan. 2012.

OCERGS. Cooperativismo: Conceitos e Princípios. Porto Alegre, RS. 2012. 9 p. Disponível em: 
<http://www.ocergs.coop.br/cooperativismo/con ceitos-principios>. Acesso em: 9 jul. 2013.

ROSALEM, V; SILVA, E. A. Gestão de cooperativas: um estudo sob o olhar do cooperado. Revista Administração Pública e Gestão Social. Minas Gerais, MG, v. 1, n. 1, 2009. Universidade Federal de Goiás Universidade Federal de Viçosa. Disponível em: <http://www.apgs.ufv.br/index.php/apgs/article/v iew/3\#.Ur45unKA3IU>. Acesso em: 10 set. 2013.

SIMIONI, F. J.; SIQUEIRA, E. S.; BINOTTO, E.; SPERS, E. E.; ARAUJO, Z. A. S. de. Lealdade e oportunismo nas cooperativas: desafios e mudanças na gestão. RESR, Piracicaba, SP, vol. 47, $\mathrm{n}^{\circ}$ 03, p. 739-765, jul/set 2009 - Impressa em outubro 2009. Disponível em: $<$ http://www.scielo.br/scielo.php?pid=S0103 $-20032009000300010 \&$ script $=$ sci_arttext $>$. Acesso em: 18 set. 2013.

SERIGATI, F. C.; AZEVEDO, P. F. de; ORELLANO, V. F. Fidelidade em cooperativas: um estudo empírico com as cooperativas paulistas. FGV-EESP, São Paulo, SP, Brasil. 2008. Disponível

em:<http://www.sober.org.br/palestra/13/1218.p df $>$. Acesso em: 18 set. 2013.

SHIMIDT, D,; PERIUS, V. Cooperativismo e cooperativa. In: CATTANI, Antonio David (Org). A outra economia. Porto Alegre: Veraz Editores, 2003.

WAAK, R. S.; MACHADO FILHO, C. P. Administração estratégica em cooperativas agroindustriais. II Workshop Brasileiro de Gestão de Sistemas Agroalimentares - PENSA/FEA/USP Ribeirão Preto-SP. 1999. Disponível em: <http://www.fearp.usp.br/egna/arquivo/13.pdf>. Acesso em: 18 set. 2013.

YIN, R. K. Estudo de caso: planejamento e métodos. 3 ed. Porto Alegre: Bookman, 2005. 